\title{
Um percurso de um professor "quanti"
}

\section{Resumo}

Este texto relembra 25 anos de experiência no ensino de métodos quantitativos para uma ampla variedade de públicos, tanto em termos de suas características sociodemográficas, quanto de seu "nível" escolar e do seu interesse em matemática e informática. O autor descreve a evolução de uma experiência alimentada por suas reflexões metodológicas com estatísticos e retorna às condições sociais concretas para aprender "ferramentas" quantitativas nas ciências sociais.

Palavras-chave: Estatística. Metodologia quantitativa. Análise de dados geométricos. Práticas culturais. Felicidade. Comparação internacional.

\section{Frédéric Lebaron}

Ecole Normale Supérieur ParisSarclay - França flebaron@yahoo.fr

\section{Para citar este artigo:}

LEBARON, Frédéric. Um percurso de um professor "quanti". Revista Linhas. Florianópolis, v. 21, n. 45, p. 293-300, jan./abr. 2020. Título original: Un parcours d'enseignant en « quanti ». Tradução: Fernando Coelho. 


\title{
A trajectory in the teaching of quantitative methods for sociologists
}

\begin{abstract}
This text analyses 25 years of experience in the teaching of quantitative methods in sociology, in front of very various publics in terms of their sociodemographic characteristics, their educational level, and their interest for mathematics and computer science. The author describes an evolution fed by methodological interactions with statisticians and analyses the concrete social conditions of learning in the field of quantitative tools for social sciences.
\end{abstract}

Keywords: Statistics. Quantitative methodology. Geometric data analysis (GDA). Cultural practices. Happiness. International comparison. 
Eu ensinei os chamados métodos quantitativos desde o início da minha carreira de professor-pesquisador em 1993-94. Primeiro foram os cursos intitulados "Dados Econômicos e Sociais" na Universidade de Paris-VIII (Saint-Denis), no segundo ano de um bacharelado (na época DEUG) em sociologia e história. Tratava-se principalmente de ensinar aos alunos, a maior parte meninas, de origem popular e muitas vezes provenientes de imigração, a comentar tabelas e gráficos simples, voltando às definições de indicadores, fontes etc. Esses eram os clássicos "trabalhos dirigidos", no sentido de que o ensino envolvia a participação dos alunos e uma troca, mesmo que uma parte fosse "magistral".

Então fui recrutado como mestre de conferências no departamento de sociologia da Universidade de Picardie-Jules Verne em 1997, em um posto com o perfil "métodos quantitativos". Tratava-se de dar Trabalhos Dirigidos (TDs) de pesquisas em que se fazia anualmente uma enquete coletiva. Os estudantes, geralmente de origem popular ou média, também eram em grande parte da região da Picardia e, às vezes, de um ambiente relativamente rural. O professor que coordenava o ensino dos métodos quantitativos era Philippe Cibois, especialista em análise de dados em sociologia, e eu trabalhava principalmente com Damien Cartron, hoje engenheiro em um laboratório de sociologia. Usávamos o Trideux, software livre criado por Philippe Cibois (https://cibois.pagespersoorange.fr/Trideux.html), que eu encontraria (Philippe e o software) alguns anos mais tarde em Saint-Quentin-en-Yvelines. Tratava-se de realizar ao longo do ano todo uma enquete coletiva sobre um tema fixado por nós, acrescentando as forças dos diversos grupos de TD para chegar a amostras corretas. Os alunos trabalhavam em grupos, na maioria das vezes em uma sala de informática equipada com computadores e softwares. Passávamos muito tempo gravando, com pequenos programas que funcionavam com o DOS, os dados obtidos pelos alunos, para que pudéssemos trabalhar com amostras maiores no final das sessões, passando de um computador para outro. A parte propriamente estatística foi limitada à produção de tabelas de contingência, e aos respectivos comentários pelos alunos, em seu relatório de final de ano. Durante um ano trabalhamos sobre o emprego de estudantes, o que nos levou a desenvolver uma nomenclatura de emprego apropriada, derivada das categorias socioprofissionais do Instituto Nacional de Estatística e Estudos Econômicos. 
Em 2002, após uma interrupção de três anos, quando retornei à Amiens: o software havia mudado e o ensino havia se tornado mais "semestral", mas o público permaneceu de forma geral semelhante em suas características (maioria de meninas, alunos de origem popular ou média, com formação secundária ES - econômica e social, L literária, às vezes S - científica e, muitas vezes, técnicas "terciárias" ou "médico-sociais", menos familiarizadas com o vocabulário abstrato das ciências sociais). Agora usávamos o software Sphinx e um colega demógrafo, Ronan Balac, assegurava os Trabalhos Dirigidos comigo na sala de informática. O programa, no entanto, estava muito próximo: iniciação ao software, realização de uma pesquisa desde a elaboração do questionário até o comentário nas tabelas de contingência. Os alunos trabalhavam em grupos independentes, inclusive ao nível dos assuntos, o que resultava em amostras menores para as pesquisas e uma divisão de temas (e também em assuntos mais “pessoais"). Trabalhávamos sempre em uma sala de computadores equipada e bem organizada. Mas não sendo o objetivo de atingir grandes amostras, isso produzia trabalhos muito interessantes, sobre assuntos que variavam da sociologia da educação, até a família e o trabalho, passando pela sexualidade etc.

Paralelamente, comecei nos anos 2000 a ensinar métodos quantitativos no terceiro ano da licenciatura e no Mestrado ( 1 1 e M2), tendo os alunos já obtido a licença e, portanto, passado pelo filtro da seleção universitária, o que me permitiu testar outros softwares (SPSS, Statistica, SPAD) e, principalmente, ensinar as noções fundamentais da abordagem estatística que recomendo, a da análise geométrica de dados (AGD). A sala de informática da Faculdade de Filosofia, Humanidades e Ciências Sociais era equipada com vários softwares, geralmente instalados a pedido de um professor, como Sphinx, Statistica, SPSS, SPAD. Nesse estágio, fazer recordações de matemática ou cursos mais avançados nesse campo se torna mais praticável do que no nível de licenciatura, onde os alunos às vezes têm uma relação muito difícil com o formalismo, o que requer apresentações bem simplificadas.

Desde 1998, eu trabalhava no grupo Rouanet, que se formou do "Grupo Matemáticas e Psicologia" de Paris-Descartes, que havia contribuído para renovar a pedagogia estatística em ciências humanas, sobretudo com uma coleção de manuais 
particularmente rigorosos e sistemáticos ("Estatística nas Ciências Humanas »), que ampliavam e esclareciam a metodologia de Benzécri, mas acrescentavam as ideias particularmente inovadoras de Rouanet ${ }^{2}$. Eu fazia a ligação com as redes de sociólogos vindos do "movimento Bourdieu” e dispersos em diversos países³

Enquanto isso, a partir de 2006, Henry Rouanet e Brigitte Le Roux imaginaram comigo e com alguns outros colegas, um "modelo de formação padrão" na AGD para doutorandos, jovens pesquisadores, engenheiros de estudos e de pesquisas, durante o período de uma semana, integrando cursos de estatística, da prática de informática com o SPAD e aplicativos para ciências sociais. Esse "modelo" foi praticado em Uppsala regularmente (a cada dois anos desde 2006), mas também em diferentes contextos, com públicos internacionais, mas também "disciplinarmente" diversos 4 : Copenhague (Dinamarca), Paris, Montreux (Suíça), Kaliningrado (Rússia), São Carlos (Brasil), Berkeley (Estados Unidos), Potsdam (Alemanha)... A última edição ocorreu em setembro de 2019 em Potsdam, com cerca de trinta participantes da Alemanha, Irlanda, Grã-Bretanha, Estados Unidos, Equador, Suécia, França, Japão, incluindo pesquisadores de carreira. A internacionalização dessa rede vai se acelerando, mesmo que os países do Sul continuem relativamente pouco presentes. No entanto, tive a oportunidade de discutir problemas de análise de dados com estudantes de vários países, especialmente do Brasil, muitas vezes iniciantes em prosopografia e desejosos de submeter suas bases à análise de dados.

A partir de 2013, retomei o ensino do Trideux na UVSQ no terceiro ano da Licenciatura, com um público de estudantes de sociologia de origem média, da região de Paris. A ideia era permitir que os alunos adquirissem noções básicas dos métodos

\footnotetext{
1 Rouanet Henry, Le Roux Brigitte, Bert Marie-Claude, Statistique en Sciences Humaines: Procédures naturelles, Paris, Dunod, 1986 ; Bernard Jean-Marc, Rouanet Henry, Le Roux Brigitte, Statistique en Sciences Humaines: Analyse inductive des données, Paris, Dunod, 1990 ; Rouanet Henry, Le Roux Brigitte, Statistique en Sciences Humaines :Analyse des données multidimensionnelles, Paris, Dunod, 1993; Rouanet Henry, Le Roux Brigitte, Statistique en sciences humaines : exercices et solutions, Paris, Dunod, 1997.

${ }^{2}$ Consultar o site de Henry Rouanet: http://helios.mi.parisdescartes.fr/ lerb/rouanet/index.html

3 Entre as publicações derivadas desses trabalhos, uma obra focada na metodologia e o estudo das práticas culturais em diferentes contextos nacionais: Frédéric Lebaron, Brigitte Le Roux (dir.), La méthodologie de Pierre Bourdieu en action. Espace culturel, espace social et analyse de données, Paris, Dunod, 2015. Fiz um balanço da primeira fase dessas relações científicas em Frédéric Lebaron, L'enquête quantitative en sciences sociales: recueil et analyse des données, Paris, Dunod, 2006. Diversas publicações em língua inglesa foram feitas a partir do final dos anos 1990.

${ }_{4}^{4}$ Tivemos estagiários especializados em arqueologia, história e vários campos das ciências humanas e sociais, além da sociologia.
} 
multivariados (ACM e regressão linear e logística) para serem "tecnicamente" autônomos em seus futuros estudos e trabalhos de pesquisa. O trabalho era realizado em grupo sobre questões escolhidas pelos alunos. Depois usei o SPAD para esse mesmo ensino, o que também fiz no contexto de ensino com estudantes envolvidos na formação em matemática e ciências da computação aplicadas às ciências humanas (MIASH), geralmente meninas, de bom nível de matemática e com uma certa curiosidade pelas ciências sociais: para este grupo, propus aos alunos a escolha de dados comparativos internacionais sobre a felicidade e o tratamento por pequenos grupos. Fiquei bastante satisfeito com esse ensino, que foi complementado por um curso de matemática pura sobre a decomposição em valores singulares, o “coração matemático" da AGD. Foi retomado por um colega que desde então passou a usar o software $\mathrm{R}$, com uma intenção semelhante. As sessões ocorreram na sala de computadores no âmbito da Faculdade de Ciências, que estava relativamente mal equipada na época, em termos de programas estatísticos propriamente ditos. O uso de R facilita a prática no computador pessoal.

Minha chegada à ENS Cachan (hoje ENS Paris-Saclay) em 2016 me permitiu investir no ensino em que havia trabalhado anteriormente como professor externo (desde a primeira metade dos anos 2000), o de "MQCS" (métodos quantitativos em ciências sociais) com estudantes de uma ENS, caracterizada por seu alto nível acadêmico e pela ótima formação em matemática (após anos de curso preparatório para as grandes escolas de letras e ciências sociais "B/L ", onde o nível de matemática é sólido). Em Cachan, esse título corresponde a uma formação avançada no uso de $\mathrm{R}$ em dados de ciências sociais e a uma metodologia na qual a AGD tem um lugar importante (com a ACM), ao lado da econometria. Continuo a apresentar as noções básicas de AGD e a conscientizar sobre a prática de softwares adaptados (SPAD, FactoMineR sob R). Tenho a sorte de poder complementar esse ensino com cursos de lexicometria, principalmente para os sociólogos que estão no nosso Mestrado em Sociologia Quantitativa há três anos. Nestes diferentes casos, os alunos têm conhecimentos matemáticos suficientes para deixar de lado as definições e os lembretes do curso e passar rapidamente "à prática" em seu computador pessoal, com muitas interações mais metodológicas.

Desde 2014, também ensino MQCS (mesmo título) no primeiro ano de Ciências Políticas de Saint-Germain-en-Laye, uma experiência muito enriquecedora diante de um 
público de bom nível educacional, de origem social geralmente favorecida, mas muito diversificado e com interesses diversos pelas abordagens quantitativas. No início, compartilhei esse ensino com um economista muito orientado à econometria, com quem introduzi trabalhos práticos sobre dados, além de uma aula magistral muito estatística, e depois, desde o ano passado, consegui completar a aula com trabalhos dirigidos na sala de informática, o que não acontecia até então (e dificultava a transmissão de conhecimentos práticos). Minha concepção da introdução da estatística de pesquisa para um público "generalista" consiste em dar todo o seu lugar à reflexão sobre as fontes, os indicadores, as categorias e sua construção, as questões de interpretação dos resultados, todo o conjunto de atitudes reflexivas que foram publicadas há muito tempo na tradição do Métier de sociologue de Bourdieu, Chamboredon e Passeron.

Por fim, concluirei esta descrição lembrando meu envolvimento no programa do curso "Sociologia quantitativa e demografia" de nossa menção em sociologia na Universidade de Paris-Saclay e no Instituto Politécnico de Paris: como corresponsável deste programa, posso medir as diferenças de abordagem de acordo com as instituições, o público e a complexidade de fazer um treinamento sociológico de alto nível em estatística.

Para aprender com essa experiência, em primeiro lugar insistiria no relacionamento reflexivo com as ferramentas e dados que devemos sempre favorecer. $O$ risco de viés técnico é permanente, porque o ensino se presta a ele: tendemos rapidamente a abandonar a metodologia em favor do ensino puramente técnico, seja matemático (viés que encontramos especialmente em economia ou em matemática) seja em informática (viés frequente em sociologia ou em informática), o que é sempre muito prejudicial. Temos de conseguir combinar as aprendizagens técnicas (tanto na informática quanto na matemática) e os longos desenvolvimentos reflexivos e metodológicos, orientados pelos problemas da disciplina, pela especificidade dos dados e pelas questões de pesquisa. Deixar um lugar muito importante na redação das interpretações estatísticas e sociológicas é talvez o que, no final, dá todo o significado ao aprendizado técnico. E minha convicção é que podemos ensinar tudo bem cedo, com os anos de aprofundamento nos permitindo de ir além em diferentes planos, tanto técnicos 
quanto reflexivos. Não há qualquer fórmula milagrosa, muito menos um software que resolverá todas as dificuldades.

\section{Referências}

BERNARD Jean-Marc, ROUANET Henry, LE ROUX Brigitte, Statistique en Sciences Humaines : Analyse inductive des données, Paris, Dunod, 1990.

LEBARON Frédéric, L'enquête quantitative en sciences sociales : recueil et analyse des données, Paris, Dunod, 2006.

LEBARON Frédéric, LE ROUX Brigitte (dir.), La méthodologie de Pierre Bourdieu en action. Espace culturel, espace social et analyse de données, Paris, Dunod, 2015.

ROUANET Henry, LE ROUX Brigitte, Bert Marie-Claude, Statistique en Sciences

Humaines : Procédures naturelles, Paris, Dunod, 1986.

ROUANET Henry, LE ROUX Brigitte, Statistique en Sciences Humaines :Analyse des données multidimensionnelles, Paris, Dunod, 1993.

ROUANET Henry, LE ROUX Brigitte, Statistique en sciences humaines : exercices et solutions, Paris, Dunod, 1997. 